\title{
Initial Basal and Bolus Rates and Basal Rate Variability During Pump Treatment in Children and Adolescents
}

\author{
(D) Günay Demir, (D) Yasemin Atik Altınok, (1) Samim Özen, (I) Şükran Darcan, (D) Damla Gökşen \\ Ege University Faculty of Medicine, Department of Pediatrics, Division of Pediatric Endocrinology, Izmir, Turkey
}

\begin{abstract}
What is already known on this topic?
While recommendations for basal rate profiles in adolescents and adults have been published before, at present there is no general consensus on how to start basal rate profiles in different age groups, and which additional factors should be considered. In general there are two different methods used. Total basal dose is divided by 24 to give the average basal rate per hour. Basal rates are increased or decreased according to fasting blood sugars. In the second method, basal insulin requirement is adjusted according to the requirement during the day.
\end{abstract}

\section{What this study adds?}

At the initiation of insulin pump therapy, the basal rates should not be set equally during the day. The basal rates should be initiated at a specific day rhythm for the age group.

\section{Abstract}

Objective: Pump-treated children with type 1 diabetes (T1DM) have widely differing basal insulin (BI) infusion profiles for specific periods of the day. The pattern of BI requirements depends on the timing and magnitude of cortisol and growth hormone secretion within each age group. In adolescents and young adults, a decreased insulin sensitivity is seen, particularly in the early morning (dawn phenomenon) and to a lesser extent, in the late afternoon (dusk phenomenon). Different approaches exist for the inititation of basal rates. However, there is a lack of evidence-based recommendation, especially in young children. Usually the basal rates are set equally throughout day and night or the day is divided into tertiles. The aim of this study was to analyze the change of the initial, equally distributed, BI rates over the first year of standard insulin pump therapy.

Methods: A total of 154 patients with T1DM, aged between 0 and $<21$ years at diagnosis, from a single center were documented. Patients were divided into five age groups according to age at pump initiation: group $1,<5$ years $(n=36)$; group 2, 5-8 years ( $n=20$ ); group 3, 8-15 years $(n=74)$; group 4, 15-18 years, $(n=19)$; and group 5, > 18 years, $(n=5)$. Distribution of hourly basal rates at the initiation of the pump and at the end of first year were evaluated.

Results: Median (range) age and diabetes duration was 14.46 (1.91-26.15) and 7.89 (1.16-17.15) years, respectively. Forty-four percent were male, $56 \%$ were female. Mean total insulin dose/kg in the whole cohort at the initiation and after one year of pump therapy was $0.86 \pm 0.23 \mathrm{U} / \mathrm{kg}$ and $0.78 \pm 0.19 \mathrm{U} / \mathrm{kg}$, respectively and differed significantly between each age group $(\mathrm{p}<0.001 ; \mathrm{p}<0.001)$. Mean daily basal rate/kg showed significant differences between the five groups $(p<0.001)$. Circadian distribution of BI differed markedly among the five age groups.

Conclusion: At the initiation of insulin pump therapy, circadian profiles by age group should be taken into account in pediatric patients to optimize basal rate faster and more easily.

Keywords: Type 1 diabetes, insulin infusion pump therapy, basal insulin, basal rates 


\section{Introduction}

Continuous subcutaneous insulin infusion (CSII) therapy is an effective and flexible method of insulin delivery, associated with improved glycemic control in children with type 1 diabetes mellitus (T1DM) (1). CSII improves metabolic control and in addition offers more flexible and more precise insulin delivery than multiple daily insulin (MDI) therapy, while increasing the quality of life of children and adolescents $(2,3,4,5,6,7,8)$. While recommendations for basal rate profiles in adolescents and adults have been published before, at present there is no general consensus on how to start basal rate profiles in different age groups, and which additional factors should be considered. In general, there are two different methods used. The first is total basal dose (TBD) when the dose is divided by 24 to give the average basal rate per hour. Basal rates are increased or decreased according to fasting blood glucose (9). In the second method, basal insulin (BI) requirement is adjusted according to the requirement during the day as defined by Bachran et al $(8,10)$.

The aim of this study was to analyze the change of the initial, equally distributed, BI rates over the first year of standard insulin pump therapy.

\section{Methods}

Patients with T1DM who were switched to CSII from a single center were documented. Participants were all on MDI therapy before CSII therapy and were counting carbohydrates. Rapid acting aspart insulin was used for insulin pumps. Total dose of insulin at the initiation of pump therapy was calculated according the mean hemoglobin A1 C (HbA1c) over the last year and was reduced by $10 \%$ if $>64$ $\mathrm{mmol} / \mathrm{mol}$ ( $>8 \%$ ), by $20 \%$ if between $53-64 \mathrm{mmol} / \mathrm{mol}(7-$ $8 \%$ ) and $30 \%$ if $<53 \mathrm{mmol} / \mathrm{mol}(<7 \%)$. Forty percent of the total insulin dose was calculated as the BI dose. According to departmental recommendations, basal rates were equally distributed hourly at the initiation of therapy, and rates are changed based on pre-meal capillary blood glucose levels and, when needed, with a fasting test over a period of six to eight hours. After initiation of CSII therapy, basal dose changes were made according to the needs of the children and adolescents. Patients were evaluated every three months, and data on $\mathrm{HbA} 1 \mathrm{c}$, weight, TBD and bolus insulin (IU/kg) doses were recorded. Participants were divided into five age groups according to insulin requirements and chronological age at pump initiation as follows: group $1,<5$ years; group 2, 5 to 8 years; group 3, 8 to 15 years; group 4, 15 to 18 years; and group $5,>18$ years $(n=5)$.
Data collection was approved by the institutional review board of Ege University and is in accordance with the Declaration of Helsinki (approval number: 20-5.1 T/29, date: 08.07.2020). The children with T1DM and their parents signed a written informed agreement and consent form, respectively, when they were enrolled in the study. Young adults $>18$ years of age signed informed agreement and consent form.

\section{Statistical Analysis}

Analysis were carried out using Statistical Package for the Social Sciences for Windows, version 25.0 (IBM Inc., Armonk, NY, USA). Descriptive statistics are reported using mean \pm standard deviation for normally distributed variables, and median (range) for skewed data. Groups are compared by independent samples t-test for normally distributed variables and the Mann-Whitney $U$ test for skewed data. Trends across more than two groups were analyzed using linear polynomial contrasts (ANOVA). A $p<0.05$ was considered statistically significant.

\section{Results}

Patient records of 154 T1DM children and adolescents, aged $<21$ years at diagnosis, between 2004 and March 2020 with a follow-up of $>1$ year on insulin pump therapy were evaluated. The sex ratio was 87 (56.5\%) girls and 67 (43.5\%) boys. Patient numbers in the five groups were: group 1 $(n=36)$; group $2(n=20)$; group $3(n=74)$; group $4(n=19)$; and group $5(n=5)$. Median age and diabetes duration of the study group was $14.46(1.91-26.15)$ years and 7.89 (1.1617.15) years, respectively. Basic characteristics of the five different age groups are presented in Table 1 . The mean total daily insulin dose (TDD) increased from the youngest to the oldest age group until the end of puberty. At initiation and at the end of the first year of pump therapy, insulin dose/kg was different in each age group $(p<0.001 ; p<0.001)$ (Table $2)$. Also, the mean daily basal rate/kg showed substantial differences between the five groups with the highest basal requirement in group $4(p<0.001)$ (Table 2$)$.

Median total insulin dose/kg at initiation and after one year of pump therapy was $0.86 \pm 0.23 \mathrm{IU} / \mathrm{kg}$ and $0.78 \pm 0.19$ IU/kg in all children with T1DM respectively. The mean BI requirement/kg at pump initiation and after the first year of therapy according to age groups are given in Table 2 .

The circadian distribution of BI differed markedly among the five age groups (Figure 1). In groups 3 and 5, BI requirement was highest between 06:00 and 09:00 but in group 4 the highest requirement was seen between 18:00 and 21:00. The lowest requirement was between 10:00 
Table 1. Patient characteristics and daily insulin requirement by age group at the initiation of pump therapy (mean \pm standard deviation, percentage)

\begin{tabular}{|c|c|c|c|c|c|}
\hline & $\begin{array}{l}0-5 \text { age } \\
(n=36)\end{array}$ & $\begin{array}{l}5-8 \text { age } \\
(n=20)\end{array}$ & $\begin{array}{l}8-15 \text { age } \\
(n=74)\end{array}$ & $\begin{array}{l}15-18 \text { age } \\
(n=19)\end{array}$ & $\begin{array}{l}>18 \text { age } \\
(n=5)\end{array}$ \\
\hline Age (years) & $2.85 \pm 1.47$ & $6.83 \pm 0.94$ & $11.62 \pm 2.12$ & $16.27 \pm 0.85$ & $19.83 \pm 1.43$ \\
\hline T1DM duration (years) & $0.76 \pm 0.92$ & $2.38 \pm 1.37$ & $4.10 \pm 3.08$ & $4.60 \pm 3.20$ & $5.70 \pm 3.23$ \\
\hline Basal insulin (\%) & $36.47 \pm 9.08$ & $38.75 \pm 7.67$ & $38.45 \pm 8.58$ & $42.89 \pm 14.59$ & $38.40 \pm 7.95$ \\
\hline Basal insulin (IU/kg/d) & $0.25 \pm 0.07$ & $0.30 \pm 0.08$ & $0.34 \pm 0.09$ & $0.32 \pm 0.11$ & $0.24 \pm 0.06$ \\
\hline TDI (IU/kg/d) & $0.69 \pm 0.14$ & $0.81 \pm 0.12$ & $0.89 \pm 0.19$ & $0.76 \pm 0.16$ & $0.63 \pm 0.08$ \\
\hline
\end{tabular}

Table 2. According to five age groups. The median basal insulin requirement per kilogram of body weight

\begin{tabular}{|c|c|c|c|c|c|}
\hline \multirow[t]{2}{*}{ Age group/n } & \multicolumn{2}{|c|}{ Pump initiation BI (U/kg/d) } & \multicolumn{2}{|c|}{ First year BI $(\mathrm{U} / \mathrm{kg} / \mathrm{d})$} & \multirow[t]{2}{*}{$\mathrm{p}$} \\
\hline & Median & $\operatorname{Min} / \max$ & Median & $\operatorname{Min} / \max$ & \\
\hline $0-5 / 36$ & 0.22 & $0.04 / 0.72$ & 0.26 & $0.10 / 0.43$ & 0.019 \\
\hline $8-15 / 74$ & 0.30 & $0.09 / 0.87$ & 0.33 & $0.17 / 0.66$ & 0.019 \\
\hline $15-18 / 19$ & 0.32 & $0.12 / 0.50$ & 0.34 & $0.10 / 0.53$ & 0.334 \\
\hline$p^{*}$ & $<0.001$ & & $<0.001$ & & \\
\hline
\end{tabular}

$\mathrm{p}$ : initial and first year basal rates in the same age group.

$\mathrm{p}^{*}$ : basal rates among age groups.

BI: basal insulin, Min/max: minimum/maximum

and 13:00 in all groups. Prepubertal children (group 1 and group 2) displayed a high peak between 22:00 and 01:00 $h(p<0.001$ and $p=0.007$ respectively) at the end of first year of therapy. While median (range) HbA1c was $7.5 \%$ (4.1-11.3) on the third month of pump therapy, it decreased to $7.1 \%(5.3-11.4)$ at the end of the first year after circadian rhythm was achieved $(p=0.001)$.

\section{Discussion}

CSII use in adolescents, children, and especially preschool children, is associated with improved glycemic control $(6,8,11,12)$. Other than achieving metabolic control, CSII has beneficial effects on psychosocial factors, physical performance, protection from long-term complications and hypoglycemia (13). Insulin requirement at the time of pump initiation depends upon the insulin dose on MDI, the level of glycemic control and the weight of the patient. According to the consensus statement from the European Society for Pediatric Endocrinology, in children with good glycemic control and a low frequency of hypoglycemia, the total dose may need to be reduced by $10-20 \%$. In a patient who has been experiencing frequent hypoglycemia, the dose should be reduced by $20 \%$ (6). According to Danne et al (14), in children with good glycemic control and a low frequency of hypoglycemia, the total dose has to be reduced by approximately $10 \%$ if using soluble regular human insulin in the pump. In case of frequent hypoglycemia, the dose should be reduced by $20 \%$. Alemzedah calculated his daily total dose as "Total dose = Body weight $\times 0.74$ " in his research with 14 children with T1DM (15). In our institution, total dose of insulin at the initiation of pump therapy is calculated according glycemic control based on HbA1c of the patient and is reduced by $10 \%$ if above $64 \mathrm{mmol} /$ $\mathrm{mol}(>8 \%$ ), by $20 \%$ if between $53-64 \mathrm{mmol} / \mathrm{mol}(7-8 \%)$ and $30 \%$ if below $53 \mathrm{mmol} / \mathrm{mol}(<7 \%)$. After calculating the basal dose as $40 \%$ of total insulin, we divided the TBD equally into 24 hours.

Studies show that total insulin dose decreases in the first year after CSII therapy. Colino et al (16) showed a decrease from 0.89 to $0.73 \mathrm{UI} / \mathrm{kg} /$ day $(\mathrm{p}<0.001$ ) in TDD at the end of the first year of pump therapy. In contrast, Ahern did not show a decrease in TDD after 12 months of insulin pump use (3). A randomized study by Doyle showed that after 16 weeks of therapy, the CSII group had a significant decrease in TDD (5). In our research we showed a decrease from 0.86 to $0.78 \mathrm{UI} / \mathrm{kg} /$ day $(p<0.01)$ in TDD at the end of the first year of pump therapy. 


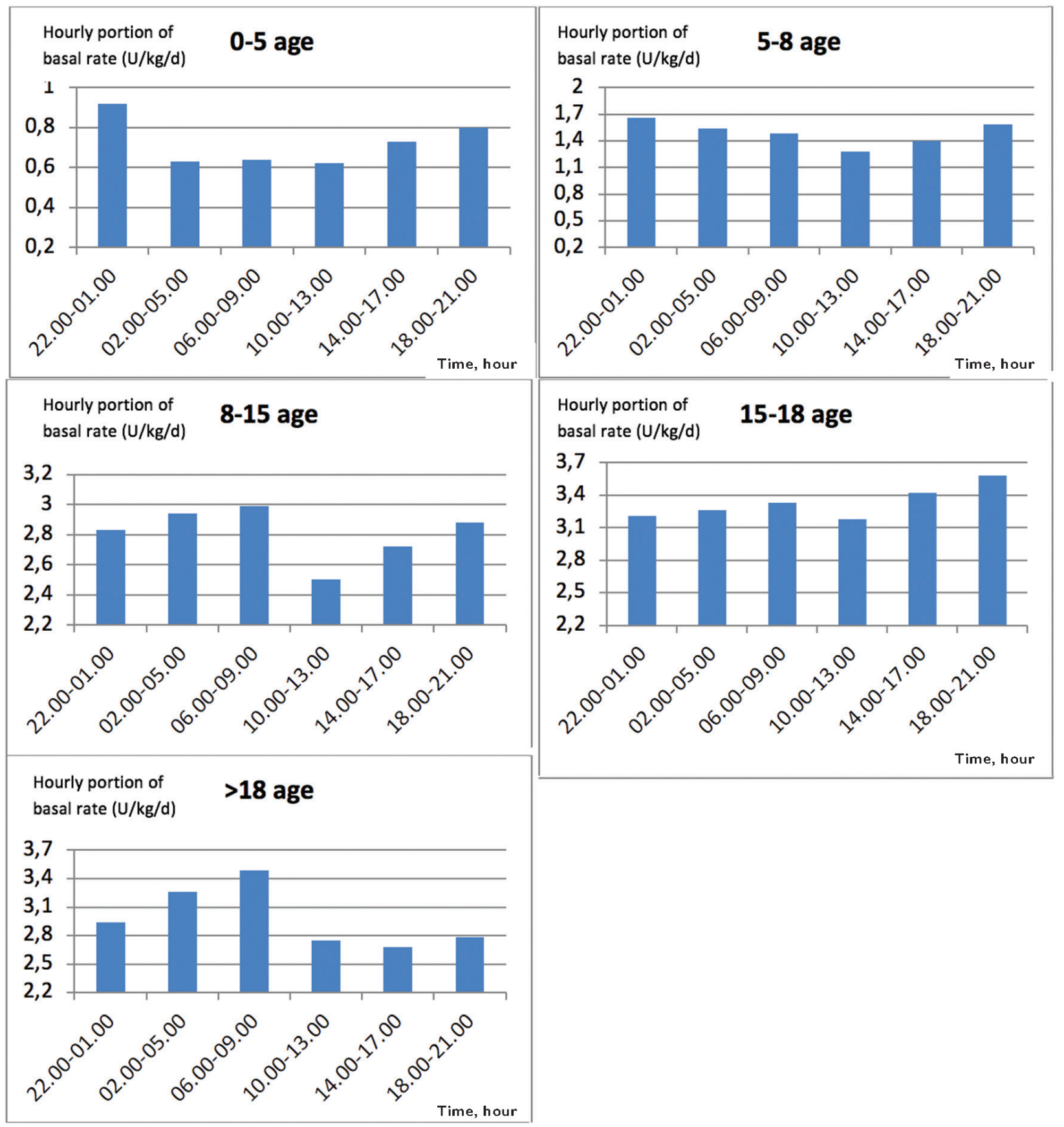

Figure 1. The mean circadian distribution of the total basal rate showed different profiles in the five age groups

In a cross-sectional, international survey of CSII in 377 children and adolescents with T1DM, the TDD of insulin was lower in the younger age groups and increased with puberty (17). In our study, the results were similar. The total insulin dose per kilogram was highest during adolescence (group 4).

CSII is the most physiological method of insulin delivery, simulating the pattern of insulin secretion with a continuous adjustable 'basal' delivery (18). Guidelines for insulin dosing basal/bolus ratio, have been established for adults with T1DM. However, these guidelines are not appropriate for children (6). According to Danne et al (14), as during injection therapy, approximately 30-40\%, rarely up to $50 \%$, of the TDD accounts for the basal rate. According to Hanas approximately $40-50 \%$ of the daily insulin requirement should be the basal rate but some children with T1D may need up to $60 \%(19,20)$. In our study, at the end of the first year, the mean basal rate of all cases was $38 \%$ and was similar to other studies. 
In children BI requirements are different in different age groups, especially in children younger than seven years of age, as well as in children who are in different stages of puberty (21). Klinkert et al (22) found that adolescents require the highest insulin doses, both as total and basal. Due to the balance of insulin and its counter-regulatory hormones, mostly the action of growth hormone, insulin requirement rises throughout puberty. According to the consensus statement from the European Society for Pediatric Endocrinology, the average TDD per kilogram of body weight should be 0.2-0.4 IU for toddlers, 0.4-0.6 IU for prepubertal children, and 0.8-1.2 IU for adolescents (6). In our study, median TDD basal per body weight was $0.18 \mathrm{IU} /$ $\mathrm{kg}$ for 0-5 age group, $0.39 \mathrm{IU} / \mathrm{kg}$ for prepubertal children, and $0.71 \mathrm{IU} / \mathrm{kg}$ for adolescents $(\mathrm{p}<0.01)$.

The pattern of BI requirements depends on the timing and magnitude of cortisol and growth hormone secretion within each age group (23). According to studies to date, basal rate profiles should be programmed in hourly intervals, according to the patient's circadian variation in insulin sensitivity $(6,8,14,19,23)$. Schreiner and Boyer (23) reported that, under twenty years of age, BI requirement often begins peaking before midnight, maintains at a relatively high level throughout the night, drops through the morning hours, and gradually increases from noon to midnight. Although no statistical difference was found in BI requirement between age groups, many adolescents experienced a midday "decrease" rather than a significant "increase" in BI requirement in this study. Twenty-four hour pattern of peaks and troughs was remarkably similar in the age group $<10$ years and the 11-20 age group. In the study of Nicolajsen (24), children with T1 DM between the ages of 3-9 years had higher basal rates late at night (10:00 pm-12:00 am), while the oldest age group had a slight increase in basal rates in the early morning (3:00 am-7:00 am) (18). The reason for the reversed dawn phenomenon in the younger age group is unclear. An emptying of the gastric contents after falling asleep could be one explanation. Gastric emptying is slow during sleep, but rapid eye movement (REM) sleep is associated with faster gastric emptying. Children who take "afternoon naps" reach REM sleep faster after sleep onset than pre-adolescents who have discontinued their afternoon naps. In two studies done in adolescents and young adults, decreased insulin sensitivity was seen, particularly in the early morning (dawn phenomenon) and to a lesser extent, in the late afternoon (dusk phenomenon). This leads to a typical two-wave basal rate profile (14). In other studies prepubertal children needed a higher basal rate late in the evening and it is common for the basal rate requirement to be higher earlier in the night (midnight to 3.00 a.m) than later on (3.00-7.00 am) (19). The PedPump Study group noted that younger children often need more BI between 21.00 and $24.00 \mathrm{~h}$ (6). In our study, the circadian distribution of the total basal rate showed characteristic profiles in the five age groups. Younger age groups had higher basal rates $(10.00$ pm-01.00 am), while the oldest age group had a slight increase in basal rates in the morning $(6.00$ am-9.00 am). Our study, like other studies, supports the high insulin requirement at early-night in the prepubertal period. We believe that adjusting the hourly BI doses according to the need instead of constant adjustment will provide faster blood glucose normalization in a pediatric population. However, since there is no consensus on basal dose adjustment according to age groups, further studies are needed in this area.

\section{Study Limitations}

This study was single center. An improvement in study design would be to conduct it as a multicenter study. This would increase the number of children with T1DM, would allow for a comparison between children with T1DM on the same hourly BI dose versus those with their BI dose adjusted to their circadian rhythm in a crossover design, which should result in more robust conclusions.

\section{Conclusion}

At the initiation of insulin pump therapy, the basal rates should not be set equally during the day but should be initiated at a specific day rhythm for the age group. Our results indicate that it is simply not reasonable to expect BI needs to be met by a flat rate of insulin delivery for 24 hours.

\section{Ethics}

Ethics Committee Approval: The study was approved by Ege University Faculty of Medicine, Ethics Committee (protocol number: 20-5.1T/29, date: 08.07.2020).

Informed Consent: Written informed consent was obtained from all participants or their parents/guardians.

Peer-review: Externally peer-reviewed.

\section{Authorship Contributions}

Surgical and Medical Practices: Damla Gökşen, Concept: Günay Demir, Design: Günay Demir, Data Collection or Processing: Günay Demir, Yasemin Atik Altınok, Damla Gökşen, Samim Özen, Şükran Darcan, Analysis or Interpretation: Günay Demir, Damla Gökşen, Literature Search: Günay Demir, Yasemin Atik Altınok, Damla Gökşen, Samim Özen, Şükran Darcan, Writing: Günay Demir, Damla Gökşen. 
Financial Disclosure: The authors declared that this study received no financial support.

\section{References}

1. Heinemann L, Fleming GA, Petrie JR, Holl RW, Bergenstal RM, Peters AL. Insulin Pump Risks and Benefits: A Clinical Appraisal of Pump Safety Standards, Adverse Event Reporting, and Research Needs A Joint Statement of the European Association for the Study of Diabetes and the American Diabetes Association Diabetes Technology Working Group. Diabetes Care 2015;38:716-722.

2. Rabbone I, Bobbio A, Berger K, Trada M, Sacchetti C, Cerutti F. Agerelated differences in metabolic response to continuous subcutaneous insulin infusion in pre-pubertaland pubertal children with Type 1 diabetes mellitus. J Endocrinol Invest 2007;30:477-483.

3. Ahern JAH, Boland EA, Doane R, Ahern JJ, Rose P, Vincent $M$, Tamborlane WV. Insulin pump therapy in pediatrics: a therapeutic alternative to safely lower HbA1c levels across all age groups. Pediatric Diabetes 2002:3:10-15.

4. Schiel R, Burgard D, Perenthaler T, Stein G, Kramer G, Steveling A. Use and Effectiveness of Continuous Subcutaneous Insulin Infusion (CSII) and Multiple Daily Insulin Injection Therapy (MIT) in Children, Adolescents and Young Adults with Type 1 Diabetes Mellitus. Exp Clin Endocrinol Diabetes 2016;124:99-104.

5. Doyle EA, Weinzimer SA, Steffen AT, Ahern JA, Vincent M, Tamborlane WV. A randomized prospective trial comparing the efficacy efficacy of continuous subcutaneous insulin infusion with multiple daily injections using insulin glargine. Diabetes Care 2004;27:1554-1558.

6. Phillip M, Battelino T, Rodriguez H, Danne T, Kaufman F; European Society for Paediatric Endocrinology; Lawson Wilkins Pediatric Endocrine Society; International Society for Pediatric and Adolescent Diabetes; American Diabetes Association; European Association for the Study of Diabetes. Use of insulin pump therapy in the pediatric agegroup: consensus statement from the European Society for Paediatric Endocrinology, the Lawson Wilkins Pediatric Endocrine Society, and the International Society for Pediatric and Adolescent Diabetes, endorsed by the American Diabetes Association and the European Association for the Study of Diabetes. Diabetes Care 2007;30:1653-1662.

7. Grunberger G, Abelseth JM, Bailey TS, Bode BW, Handelsman Y, Hellman R, Jovanovič L, Lane WS, Raskin P, Tamborlane WV, Rothermel C. Consensus Statement by the American Association of Clinical Endocrinologists/American College of Endocrinology insulin pump management task force. Endocr Pract 2014;20:463-489.

8. Bachran R, Beyer P, Klinkert C, Heidtmann B, Rosenbauer J, Holl RW; German/Austrian DPV Initiative; German Pediatric CSII Working Group; BMBF Competence Network Diabetes. Basal rates and circadian profiles in continuous subcutaneous insulin infusion (CSII) differ for preschool children, prepubertal children, adolescents and young adults. Pediatr Diabetes 2012;13:1-5. Epub 2011 May 5

9. Walsh J, Roberts R. Pumping Insulin: Everything You Need for Success on a Smart Insulin Pump, 4th ed. San Diego, CA: Torrey Pines Press, 2006

10. King $\mathrm{AB}$. Reassessment of insulin dosing guidelines in continuous subcutaneous insulin infusion treated type 1 diabetes. Curr Diab Rep 2014;14:503.
11. Pickup JC, Hammond P. NICE guidance on continuous subcutaneous insulin infusion 2008: review of the technology appraisal guidance. Diabet Med 2009;26:1-4

12. Danne T, Bangstad HJ, Deeb L, Jarosz-Chobot P, Mungaie L, Saboo B, Urakami T, Battelino T, Hanas R; International Society for Pediatric and Adolescent Diabetes. ISPAD Clinical Practice Consensus Guidelines 2014. Insulin treatment in children and adolescents with diabetes. Pediatr Diabetes 2014;15(Suppl 20):115-134.

13. Scheidegger U, Allemann S, Scheidegger K, Diem P. Continuous subcutaneous insulin infusion therapy: effects on quality of life. Swiss Med Wkly 2007;137:476-482.

14. Danne T, von Schütz W, Lange K, Nestoris C, Datz N, Kordonouri O. Current practice of insulin pump therapy in children and adolescents the Hannover recipe. Pediatr Diabetes 2006;7(Suppl 4):25-31.

15. Alemzadeh R, Hoffmann RG, Dasgupta M, Parton E. Development of optimal kids insulin dosing system formulas for young children with type 1 diabetes mellitus. Diabetes Technol Ther 2012;14:418-422. Epub 2012 Jan 12

16. Colino E, Martín-Frias M, Yelmo R, Álvarez MÁ, Roldán B, Barrio R. Impact of insulin pump therapy on long-term glycaemic control in a paediatric Spanish cohort. Diabetes Res Clin Pract 2016;113:69-76. Epub 2016 Feb 1

17. Danne T, Battelino T, Kordonouri O, Hanas R, Klinkert C, Ludvigsson J, Barrio R, Aebi C, Gschwend S, Mullis PE, Schumacher U, Zumsteg U, Morandi A, Rabbone I, Cherubini V, Toni S, de Beaufort C, Hindmarsh P, Sumner A, van Waarde WM, van den Berg N, Phillip M. A crosssectional international survey of continuous subcutaneous insulin infusion in 377 children and adolescents with type 1 diabetes mellitus from 10 countries. Pediatr Diabetes 2005;6:193-198.

18. Shalitin S, Phillip M. The use of insulin pump therapy in the pediatric age group. Horm Res 2008;70:14-21. Epub 2008 May 21

19. Hanas R. Selection for and initiation of continuous subcutaneous insulin infusion. Proceedings from a work shop. Horm Res 2002;57(Suppl 1):101-104.

20. Litton J, Rice A, Friedman N, Oden J, Lee MM, Freemark M. Insulin pump therapy in toddlers and preschool children with type 1 diabetes mellitus. J Pediatr 2002;141:490-495.

21. Cemeroglu AP, Thomas JP, Zande LT, Nguyen NT, Wood MA, Kleis L, Davis AT. Basal and bolus insulin requirements in children, adolescents, and young adults with type 1 diabetes mellitus on continuous subcutaneous insulin infusion (CSII): effects of age and puberty. Endocr Pract 2013;19:805-811.

22. Klinkert C, Bachran R, Heidtmann B, Grabert M, Holl RW; DPV-Initiative. Age specific characteristics of basal insulin-rate for pediatric patientds on CSII. Exp Clin Endocrinol Diabetes 2008;116:118-122. Epub 2007 Oct 31

23. Schreiner G, Boyer BA. Characteristics of basal insulin requirements by age and gender in Type- 1 diabetes patients using insulin pump therapy. Diabetes Res Clin Pract 2005;69:14-21. Epub 2004 Dec 22

24. Nicolajsen T, Samuelsson A, Hanas R. Insulin doses before and one year after pump start: children have a reversed dawn phenomenon. J Diabetes Sci Technol 2012;6:589-594. 